\title{
Sri Lanka Administrative Service (1963-2013): A Fifty Year Legacy
}

\author{
V.K.Nanayakkara ${ }^{1}$ \\ SLJDA 2015 (5): 79-93
}

A new era began in the Sri Lankan public service on the First of May 1963 with the establishment of the Ceylon Administrative Service (CAS), predecessor of the Sri Lanka Administrative Service (SLAS). A golden jubilee of a service is an appropriate occasion to reflect on its genesis, its role, its achievements and its disappointments.

Keywords : Ceylon Civil Service (CCS), Sri Lanka Administrative Service (SLAS), governance, civil administration

\section{Colonial legacy}

The Ceylon Civil Service (CCS) established by Governor North in 1802 was the precursor of the Ceylon Administrative Service. The failure of the Madras Civil Service introduced in 1796 in the Maritime Provinces compelled the British to establish a separate civil service to guarantee a stable administration. (Warnapala.(1974: 32). The British pledged in 1815 to safeguard the traditional feudal administrative system by assuring the local chieftains the rights, privileges and powers of their respective offices in accordance with the traditional laws, institutions and customs. ${ }^{2}$ The occupation of the Kandyan provinces in 1815 necessitated an expansion of the civil service to administer the kingdom. Retaining the native system of government in terms of Article 8 of the Convention, the Governor, acting on behalf of the British King administered the country according to its time-honoured customs.

1 V.K.Nanayakkara served the Sri Lanka Administrative Service for 37 years. Among his multiple assignments in the Government of Sri Lanka, he was Secretary to the Prime Minister, Secretary to the Project Ministry of Environment, Secretary, Ministry of Housing and Urban Development and Secretary, Ministry of Education and Cultural Affairs.

2 Article 4 of the Kandyan Convention signed between Governor Robert Brownrigg and the principal Kandyan chiefs stated: "The Dominion of the Kandyan Provinces is vested in the Sovereign of the British Empire, and to be exercised thro the Governors or Lieut Governors for the time being and their accredited Agents; Saving to the Adikars, Dessaves, Mohottalas, Coraals, Vidanes and all other Chief and Subordinate Native Headmen, lawfully appointed by authority of the British Government, the Rights, Privileges and Powers of their respective offices, and to all Classes of People the safety of their persons and Property, with their civil rights and immunities, according to the Laws, Institutions and Customs established and in force amongst them." Kandyan Convention. Legislative Enactments of the Democratic Socialist Republic of Sri Lanka. Vol XX. Cap 637. pp. XX/310-XX/318. 
The civil service in Sri Lanka, as in the case of its neighbours, was an off shoot of the British administrative system that evolved to form the source of all authority. Consequently, the history of British rule in the country is the history of the civil service.

During the entirety of the $19^{\text {th }}$ century, the CCS remained the apex administrative organisation and a handful of officers constituted into this service controlled and ruled the country, making use of indigenous feudal administrators. It emerged as a service based on patronage, facilitated by the Haileybury entrance examination, which itself was based on public school standards.

The year 1833 was a landmark in Sri Lanka's public administration as the public service was freely made open to all classes of persons according to their qualifications. The civil service was at its peak exercising absolute rule for a century thereafter. Until the emergence of the nationalist movement in the first decade of the twentieth century, its supremacy was not challenged. The civil service that formed the basis of bureaucratic administration despite being efficient and relatively impartial, was an exclusive, centralised, regulatory, rigid and, at times, oppressive elitist group from the inception. It was the most important instrument that Britain used to perpetuate its control over the Island. The early appointees were from social and economic circles having access to the patronage of the Secretary of State with the junior ranks being filled locally by the Governor.

A major reorganisation of the colonial public service was the introduction of the competitive principle of recruitment to the civil service apparently influenced by the Northcote-Trevelyan reforms of 1854 in Britain. While agreeing that some specialist positions required "scientific and other attainments", Northcote and Trevelyan were primarily concerned in attracting liberally educated generalists, who would have the chance to move up to the relatively small number of "superior situations" that really mattered for the running of the country. After 1856 the Colonial Office substituted a competitive examination to get as Writers university graduates who had received a liberal education. ${ }^{3}$ However, it was only in 1870 that patronage as the mode of recruitment gave way to a merit based system through open competitive selection with the simultaneous holding of the examination in England and Ceylon permitting Ceylonese candidates also to sit. The CCS became the backbone of the British Empire in Sri Lanka.

3 The Indian Civil Service (ICS) which had its genesis in the untrained, underpaid and greedy underwriters of the East India Company grew to become the 'steel frame' of the British Raj, and gave way to today's Indian Administrative Service (IAS) and other all-India and central services. 
To the credit of the British it must be said that they did gradually introduce Ceylonisation of the Service so that in 1948 when Sri Lanka became independent there was no public service vacuum as happened in British ruled East and West Africa.

What was expected of the colonial public servants? He was to function as an interpreter and mediator between the colonial power and the rest of the countrymen. English instruction was imposed in schools for the purpose of obtaining qualified Ceylonese for government employment in a clerical underclass, since the country could ill afford to pay a large staff of European civil servants (Mendis.1944: 41).

Every word of the well-known and now infamous dictum of Lord Macaulay in his minute on Indian education wherein he made a vigorous plea for spreading Western learning through the medium of English, applies equally to Sri Lanka. It is apt to quote his minute explaining the purpose of English education in British India (1835): “... We must at present do our best to form a class who may be interpreters between us and the millions we govern; a class of persons, Indian in blood and colour but English in tastes, in opinion, in morals and in intellect ..." (Macaulay quoted in Young. 1957: 729). Nehru called it education for clerks for the British Raj. The minority who could afford further education in the English medium got to the coveted posts in the civil service. Accordingly, the Ceylon Administrative Service (CAS) was a prestigious colonial legacy.

At the transfer of power in 1948, Sri Lanka inherited a centralised and hierarchical administrative system. It retained the basic structures and character of a colonial public service, even after independence, which opened up new challenges before the country. The authoritarian pattern of the colonial personnel systems, with its superior cadre of the Ceylon Civil Service monopolised the top ranking positions and the native chiefs dominated the grass roots level administration until the early 1960s. Civil servants were recruited by open competitive examination, while nonCCS officers were appointed at various times to various departments on a purely ad hoc basis, their suitability being assessed only by an interview.

A significant development that contributed to the rapid growth of the government sector was the expansion of State activity undertaken by the independent nation. The post independent governments too had relied to a great extent on the organised public services as part of the structure of administration for purposes of development.

The small intake into the CCS was inadequate to provide the personnel to fill the administrative posts created by such expansion. Qualitatively, there was little difference between the successful CCS candidates and 
those who had just missed gaining entry into the service at the CCS examination. Inevitably, the larger cadre of non-CCS departmental officers would agitate for the abolition of the privileged position of the CCS and demand a unified service.

The question, however, arose whether this country should continue with the CCS which had served the imperial interests to maintain the undisputed sway of the British Crown. Administrators come from specific social classes and their behaviour is influenced by their social origin. But is there a necessary linkage between the social background of the administrators and the way they take their decisions in office? The need for the creation of a unified administrative service was articulated by the political leaders in the immediate aftermath of independence. J.R. Jayewardene, Minister of Finance mooted this idea on 19 November 1951: "The need for a unified administrative service for manning all senior and junior administrative posts in departments, other than those acquiring professional - or highly specialised knowledge and experience, has become increasingly evident in recent times." Further, the socio-cultural orientation of the new peoples' regime brought into power at the General Election of 1956 was different from the views of the privileged members of the CCS. The English educated CCS elite was viewed with disfavour by the new political leadership who considered the service as being unsympathetic with the hopes and desires of the social classes which the 1956 regime represented.

\section{Unified Administrative Service}

From independence in 1948 to 1956, the Government of Sri Lanka (GOSL) made no effort to restructure the public service despite demands by opposition political parties for revamping the system inherited from the colonial masters. After 1956, charges of non-cooperation were levelled against the CCS. Allegedly, the bureaucracy represented the interests of the colonial ruler and was not responsive to the progressive policies of the new government. This was mainly due to the background and orientation of the elite CCS who were not different from the departed colonial rulers. Yet, elitism is not synonymous with neutralism or with fair play.

The Wilmot A. Perera Commission of 1959-61 having examined all the grades of officers performing administrative functions concluded that the continuation of the Ceylon Civil Service (CCS) amounted to 'perpetuating a caste system the entry into which is based on mere chance'. The Commission underlined the need for unification of the administrative grades: 
"The need for unifying all administrative grades in the Public Service has long been recognised as a reform that was urgently necessary. By unification is meant the absorption into one common group, of officers of the present Ceylon Civil Service and all other officers performing administrative functions in various departments, who do not belong to the Ceylon Civil Service. The existence of these two sets of officers on different salary levels and with different promotion prospects has created, as it were, a "caste" system which, besides being a constant source of irritation and discontent, has created a division in an important level of the Public Service." (Wilmot A. Perera Commission, 1961: 161)

Based on its recommendations, the new government elected in July 1960 implemented a number of changes in the public personnel system. At the top of the machinery of government, the elite Ceylon Civil Service (CCS) was abolished and a unified administrative service was created in its place in 1963. At the lower levels, the Village Headmen System too was abolished.

Prior to the creation of the CAS, the administrative positions in the public service were shared by two classes of officers. The first comprised the officers that belonged to the CCS, a single, dominating, elitist, generalist service which occupied the top positions and whose members were transferable across the departments. The second comprised the departmental services- allied and subordinate officers, such as the Divisional Revenue Officers, District Land Officers, Land Development Officers, Assistant Commissioners of Local Government, and Assistant Commissioners of Cooperative Development etc. who were non-transferable. An anomaly was seen in the fact that an Assistant Commissioner of Cooperative Development could rise up to the position of a senior Deputy Commissioner but never aspire to the position of Commissioner of Cooperative Development which was reserved for a CCS officer.

The creation of a unified service resulted in the replacement of the CCS and the amalgamation of posts hitherto belonging to the CCS and other departmental posts into a single administrative service.

This new system permitted the inter-departmental mobility of persons which provided the administration an opportunity to draw personnel to man positions in higher echelons of the service from a larger pool of trained officers. 
Although the Wilmot A. Perera Commission proposed six classes the new service was structured to consist of five classes, Class V being the lowest and Class I the highest. The new classes I and II corresponded to Classes I and II of the CCS. The heads of larger departments fell into these two classes. Class III corresponded to Class II Grade I of the former CCS and included heads of smaller departments and deputies of larger departments. Class IV included the senior administrative staff posts. Class V incorporated almost all the junior staff administrative posts in the public service. However, the mass of representations received by an S.F. Amerasinghe Committee clearly showed that the scheme adopted for setting up the CAS had given dissatisfaction to a large section of officers affected by it. (Sessional Paper VI-1966: 48)

The SLAS officers carry high respect and stature in society making it one of the most desirable jobs in the Island. They hold key positions in the Central Government, Provincial governments and Public Sector Undertakings. The respective Provincial Governments cannot censure or take disciplinary action against an SLAS officer serving them on secondment. The power of the SLAS bureaucracy should be measured not by the number of its members, but rather by the extent to which appointed officials have discretionary authority- that is, their ability to choose courses of action and to make policies that are not spelled out in advance by law.

The entry into service is mainly through an open competitive examination on the lines of the former CCS examination which consists of a written test and a viva voce. Graduates in the 22-28 age group would qualify for the open intake. The limited competitive stream consists of 20 percent of the intake which is again based on a written test and a viva voce for persons with experience in the public service. The examination for getting into SLAS is conducted by the Public Service Commission (PSC). Repeated attempts for getting entry are allowed twice for both open and limited candidates.

Entry into the SLAS is considered difficult. For example, the number selected for the open competitive stream for the past three occasions was as follows ${ }^{4}$ :

4 Based on information furnished by Ranjith Ariyaratne, Secretary, State Administrative Service Association and Viraj Tillekeratne. Assistant Director, Combined Services Division, Ministry of Public Administration. 21 August 2013. 
Table 1

SLAS (Open) candidates sitting the examination and the number selected

\begin{tabular}{|c|c|c|c|c|c|}
\hline Year & Sinhala & Tamil & English & Total & No. recruited \\
\hline $2009 / 10$ & 25722 & 4373 & 548 & 30643 & 131 \\
\hline $2010 / 11$ & 11458 & 1429 & 158 & 13025 & 256 \\
\hline $2011 / 12$ & 12340 & 1092 & 91 & 13423 & 112 \\
\hline
\end{tabular}

SLAS posts are classified into classes and grades. For the first time, candidates who had education in the swabhasha media also joined the public service in droves, enriching it with their sound commonsense. The following table sets out the changing class structure of the SLAS cadre as it evolved from 1963:

Table 2

Class structure and cadre of the SLAS

\begin{tabular}{|c|c|c|c|c|c|}
\hline & $\mathbf{1 9 6 3}$ & & $\mathbf{1 9 8 6}$ & & $\mathbf{2 0 0 5}$ \\
\hline Class I & 20 & Class I & 191 & Class I & 507 \\
\hline Class II & 30 & Class II/I & 382 & Class II & 635 \\
\hline Class III & 60 & Class II/II & 1145 & Class III & 1059 \\
\hline Class IV & 125 & & & & \\
\hline Class V & 845 & & & & \\
\hline Total & $\mathbf{1 , 0 8 0}$ & & $\mathbf{1 7 1 8}$ & & $\mathbf{2 4 0 1}$ \\
\hline
\end{tabular}

By 2005, the cadre of the SLAS had increased by 122 percent during a 42 year period of its existence. Table 3 comparing its cadre with related indices reveals how its cadre has kept pace with other socio-economic parameters.

Table 3

Comparison of cadre related indices

\begin{tabular}{|c|c|c|c|c|}
\hline & $\mathbf{1 9 6 3}$ & $\mathbf{1 9 8 6}$ & $\mathbf{2 0 0 5}$ & \% increase \\
\hline SLAS cadre & 1080 & 1788 & 2401 & 122 \\
\hline Number of Ministries & 24 & 43 & 83 & 246 \\
\hline $\begin{array}{c}\text { Parliamentary } \\
\text { Constituencies }\end{array}$ & 89 & 161 & 225 & 153 \\
\hline Population & $10.5 \mathrm{~m}$ & $15.4 \mathrm{~m}$ & $19.7 \mathrm{~m}$ & 88 \\
\hline
\end{tabular}


All appointments in the SLAS are subjected to public competition for the whole country which makes it one of the most competitive selection processes in the Island. For instance, the SLAS intake for the open stream in 2009/10 was 131 out of 30643 candidates which is an acceptance rate of 0.42 per cent. The successful candidates in the open stream, called probationers have to undergo a three year period of probation. Their rank in the service is determined by the date of their confirmation at the end of the period of probation.

While the SLAS minute of 1963 provided for a classification of posts according to grades, the minute introduced in 1971 repealed such classification and permitted appointment of an officer of Class III with eight years of service as Deputy Head of Department, and an officer with ten years of service and in Class III as eligible for appointment as Head of Department. Classification was reintroduced. Due to the relaxation in the system of grading posts, it was not possible to confine appointments to specific posts from those who belonged to the appropriate class or grade.

The absence of a well-conceived placement policy for the SLAS constitutes a serious breach in the system. Not only has this feature negated the entire investment on training and career development, but it has also demoralised the entire service. In the absence of a proper performance evaluation system, one always has an opportunity to continue in a given position until such time as something untoward happens to replace him. There is no system of assigning an officer to a post for a specific period, so that he is motivated to make his contribution within that time frame. This has contributed to the lowering of performance standards, reducing morale leading to a lack of motivation to excel in the job. An SLAS officer specially selected and trained for an exclusive purpose should be assigned the task for which he is trained. His role should lead him to new vistas, imaginative approaches to problem solving and a greater dynamic role in nation building.

Under British rule, the members of the Ceylon Civil Service were trained at the East India College of Haileybury in England. Now, SLAS officers, once recruited, undergo compulsory training at the Sri Lanka Institute of Development Administration. At this staff college, they are taught public administration, law, economics, management and English language. Moreover, village visits are organized to sensitise the officer trainees to the reality of rural Sri Lanka. But beyond this academic course, the faculty members try to develop an esprit de corps among their young colleagues, in spite of their different backgrounds. 
As the premier service in the Island, the SLAS offers an attractive and challenging career. Fame and glamour are also associated with this service. Even though most people tend to think that being the District Secretary (Government Agent) is the most powerful and glamorous post, the SLAS holds power at all levels. It is the service that is meant to place people straight at the top of any government organization and not the province and district alone. Most SLAS officers start their careers at the divisional level as an Assistant Divisional Secretary. They mature basically through a process of serving in a number of important positions which provides them a world view of problems.

The SLAS handles affairs of the government. At the central level, this involves the framing and implementation of policy. At provincial/ district level, it is concerned with public affairs, including development functions. At the divisional levels, the SLAS officers look after law and order, general administration and development work.

Members of the SLAS hold various administrative posts like District Secretary, Heads of Departments, and Heads of Public Enterprises. They can also be posted on deputation to the Provincial Government to various posts.

What about the security of tenure of the higher civil service? The English Common Law doctrine of pleasure was kept alive in post-independent Sri Lanka. Following on the 1946 and 1972 Constitutions, Article 55 of the 1978 Constitution laid down that all public officers held office at pleasure. Framers of the Constitutions made it the most important pillar on which rested the government's control and power of discipline over its servants. They adopted the maxim durante bene placito (during good pleasure) with some safeguards. The Government wanted the employees to realise that the State was the master who holds the whip-hand. Yet it was strongly contended on behalf of public officers that the pleasure principle is a relic of a feudal age. Until the Seventeenth Amendment to the 1978 Constitution, the public service position may be described as 'pleasure tenure' subject to Fundamental Rights and the observance of the principles of natural justice.

Were the laudable objectives of forming a unified Administrative Service achieved? With the new service, the departmental cadres of Assistants and Deputies were available for transfer to any agency at the sufferance of the specialisation of the Department. The new class of administrators the cult of the amateur- could only become masters of bluff as they move from department to department assuming responsibility for subjects on which they cannot hope to be thorough. 
There are many opposing views on the creation of a unified service. Former CCS officials have denigrated the formation of the CAS as the beginning of the present plight of public administration in Sri Lanka. Somasunderam rebukes the notification proclaiming the creation of the CAS on $1^{\text {st }}$ May 1963 'as a suicide note of a nation'. (Somasunderam: 340). He admonishes the absorption of every single executive and semiexecutive in administrative positions into the SLAS without a review of their capabilities as a genetic inheritance at birth. An opposing point of view posits that the elitist CCS failed to reckon the socio-economic changes of a developing nation.

D. Wijesinghe sums up the ensuing deterioration of standards as follows:

The abolition of the Ceylon Civil Service and the creation of a unified Administrative Service in its place is not considered as an 'unmixed blessing'. Infact, apart from thenatural antipathy towards this move by the old guard, there is a genuine belief among many that this move resulted in lowering the standards and ultimately the performance at the highest levels of the administrative set-up in the country. (Wijesinghe. 1997: 18)

\section{Pressures and responses}

From enforcement of law and order and collection of revenue, the post-independence public service has grown as an important tool for implementing State policies of welfare and planned economic development. These new tasks and objectives led to an increase in the size of the bureaucracy. What was the impact of five decades of involvement by the SLAS bureaucrats in nation-building and socio-economic development? Transforming the inputs received into development outputs failed to enhance the quality of life or satisfy the basic needs. The complexity of problems and the issues which are common to any post independent nation were aggravated during the $60 \mathrm{~s}$ and the $70 \mathrm{~s}$ by deliberate political, social and economic changes that were imposed by successive governments. Associated with these changes was a wide variety of extraneous factors, which contributed to the dilution of quality of the SLAS in particular, and the public service of Sri Lanka, in general. The cardinal principles of public service, namely, professionalism, anonymity, integrity and neutrality, are slowly withering.

The post 1963 era witnessed several trends - decentralisation, politicisation and people's participation. These trends affected the SLAS to a great extent. Decentralisation took two forms. Under de-concentration, field functions were increasingly assigned to Assistant Government Agents 
(AGAs). Its other form, devolution, itself posed challenges. As part of greater politicisation, we witnessed a Public Service Commission subject to Cabinet control and the institution of a District Political Authority, a District Minister, and a Chief Minister. The DRO (and later the AGA) transformed himself to a Divisional Secretary; the Government Agent transformed himself to a District Secretary. With the abolition of the independent PSC in 1972, the powers of recruitment, transfer and disciplinary control of public officers were vested in the Cabinet. The resulting enhanced politicisation of the working environment made independent and objective decision making increasingly difficult. A tendency for Ministers and other politicians to interfere in routine administrative activities has long been evident.

Do SLAS officers offer free and frank advice to Ministers? Such advice must be honest, impartial and comprehensive and not always be what Ministers want to hear. A negative outcome of politicising the higher civil service is that political executives may be surrounded by "yes people" who act as promoters for a particular position rather than pointing out the risks in a particular policy or approach and where possible suggesting alternatives that might have a more effective result for the issue being addressed. If, instead of contributing frank advice, its members deepen even more their partiality by acceding to politician's requests, then the whole institution loses its raison d'être.

Despite the nexus between politicians and SLAS bureaucrats, the latter are always in an insecure position since they can be arbitrarily transferred at any time, especially if they threaten certain local vested interests. Perversely, officers of integrity who, in applying the rules diligently, act against offenders aligned with the ruling party in the government, suffer the harassment of repeated transfer by telegram. This applies particularly to those involved in provincial, district and divisional level administration. Moreover, the Ministry of Public Administration maintains a 'public officers pool' until the transferred officials are found alternative placement. Whenever there is a change of government, the SLAS officers have to face large scale transfers. Subservience to the ruling regime has become the driving force of the public servant rendering him a "servant of the ruling party."

According to the Weberian construct, a public official has to be of 'steel frame' with rules, regulations and procedures governing the day-to-day functioning of the higher civil service. Allegedly, the SLAS is seen as too inflexible and rule bound to respond to changing needs. Manuals and routine takes precedence over creativity. Purportedly, seniority is regarded in greater esteem than merit. Hierarchy acts as the backbone 
of the system. For most people and politicians, SLAS bureaucracy is a pejorative term implying red tape, waste, rigidity, inefficiency, buck passing, authoritarianism and insensitivity. Result-orientation is not the goal, procedural accountability takes a lead over performance, and faithful execution of orders is done single-mindedly without giving any regard to the final outcomes. Decisions do not emerge out of discussions and consensus.

In 1945, Sinhala and Tamil were made the media of instruction in all State, assisted and private primary schools in the country. The switchover of the medium of instruction in secondary education was effected much later in the nineteen fifties. Swabhasha was introduced in secondary education year by year, with Grade 6 in 1953, progressing to Grade 12 (the final grade then) in 1959. The introduction of Sinhala and Tamil as media of instruction in university education (Faculty of Arts changed the medium of instruction to Sinhala and Tamil in 1960) preceded the establishment of the CAS by three years.

The implications of these policies were visible at all levels throughout the public service. The impact of changing socio-economic forces was visible in the CCS itself, during the last stages of its existence. Other professions such as, engineering, medicine and accountancy which were insulated for a long time from the changes that took place in the medium of instruction, had also demonstrated these falling standards in the recent years. When tested in managerial/administrative positions, members of other professions too displayed the inability to cope with the challenges of changing times.

SLAS officers act more as generalists and much less as specialists. Their mobility between jobs and the job content that entails administrative or executive activity portrays an SLAS officer as a generalist. In the British context, the concept of a generalist is used in the sense of a gifted amateur or an all rounder based largely on a liberal education. The induction training has been planned in such a way that barely any scope is left for giving a non-generalist orientation. Once they join the service they are shuffled for short spells from one to the other department, so much so that they scarcely get a chance to develop a technical expertise. Nevertheless, specialisation of a high degree is required to handle complex tasks at the Ministries of Finance, Agriculture, Irrigation, Commerce, Power and Energy, Petroleum, and Transport, etc.

Reforming the SLAS is not an easy task. Successive commissions and committees for administrative reforms have submitted reports and recommendations over the years, without bringing any fundamental 
change to the institution. The SLAS officers form a powerful lobby at the national level, and they will certainly resist any proposal that threatens their position, even when the objective is to make them more professional and accountable to the public, especially by removing the constitutional protection given to them.

\section{Way ahead}

Has the SLAS proved itself capable of adaptation and adjustment throughout half a century of dynamic socio-political and economic restructuring? It is the successor to a career civil service influenced by Northcote and Trevelyan (1854) to serve a 'regulatory state' of the kind envisaged by the classical economists and subsequently the Keynesian welfare state during the Second World War and immediately afterwards.

In the early days of the service, many of the brightest university graduates were attracted to the SLAS. However, it is no longer the case. Current graduates do not value the SLAS or for that matter any public service to the extent seen earlier. Furthermore, the Executive Presidency after the Eighteenth Amendment has applied a stricter test of loyalty in its selection to senior positions. Other conditions, such as relatively lower pay scales compared to the private sector have further impeded the recruitment and retention of high quality employees.

There has been a growing debate over politicisation which is damaging the service. The ethos of the service probably changed under semipresidentialism. The executive presidency, some critics allege may coerce SLAS officers to lose their detachment and become too eager to please their political masters. Apparently, the gap between politicians' rhetoric, public expectations and the day-to-day dilemmas facing managers wanting to improve the quality of the public services is increasing. The ethos is one of public service rather than of business. Despite a Ministry of Public Management Reforms, the SLAS still essentially constitutes a system of public administration rather than of public management.

The crucial questions are these. How well has the SLAS worked during the past fifty years? According to Somasunderam 'the SLAS had not measured up to its expectations.' (Somasunderam: 356). And how well has it worked compared to the 150 years of the CCS? Resulting in a paradigm shift in the 'managing of government', the rule-bound bureaucracy of the sixties had to face multiple roles of development administrator, catalyst, change agent, management professional and public manager. 
However, the journey of the SLAS for the last fifty years has been quite tumultuous. In the twenty first century, new threats, new demands, new expectations and new frontiers have arisen. The working context of the SLAS officer has changed. The ethos of selfless public service has been substituted by the market. The welfare/developmental State has been replaced by the disciplines of business in the enterprise state. The accelerating rate of social and technological change and the resulting increasingly multifaceted managerial tasks demand exceptional expertise on the part of public administrators. The public space is being redrawn and government reinvented (Osborne and Gaebler, 1992). In a further paradigm shift the new public management (NPM) is being replaced by a 'new public service'. ${ }^{5}$

Nonetheless, the SLAS has served the nation commendably as an effective binding force of the country, as well as sustaining in the face of political upheavals, national calamities, insurgencies and terrorism under trying conditions for over five decades. It has proved itself capable of adaptation and adjustment throughout a half a century of dynamic political, economic and social restructuring. The need of the future is a cadre of dedicated SLAS managers based on a professionally oriented, technically competent, politically and ideologically neutral bureaucracy.

\section{References}

Denhardt, Janet V and Robert B. Denhardt. (2011). The New Public Services: Serving not Steering. New York: M.E. Sharpe Inc.

Government of Sri Lanka. Report of the Salaries and Cadre Commission 1961. Part I- Salaries and Connected Matters. Sessional Paper III- 1961. Colombo: Ceylon Government Press.

Kandyan Convention. Legislative Enactments of the Democratic Socialist Republic of Sri Lanka. Vol XX. Cap 637. pp. XX/310-XX/318.

Macaulay, Thomas Babington. "Minute on 2 February 1835 on Indian Education" in G.M.Young. (1957). Macaulay, Prose and Poetry. pp. 721-24. Cambridge MA: Harvard University Press.

G.C. Mendis. (1944).Ceylon under the British. Colombo: The Colombo Apothecaries Co. Ltd.

Report of the Committee Appointed to report on the Ceylon Administrative Service. Sessional Paper VI-1966. Government Press. Ceylon.

Somasunderam, M. “Sri Lanka Administrative Service" M. Somasunderam (ed.). The Third Wave: Governance and Public Administration in Sri Lanka. Colombo: International Centre for Ethnic Studies.

Warnapala, W.A.Wisva. (1974). Civil Service Administration in Ceylon: A Study in Bureaucratic Adaptation. Colombo: Department of Cultural Affairs

5 See Janet V. Denhardt and Robert B. Denhardt. (2011). The New Public Services: Serving not Steering. New York: M.E. Sharpe Inc. This widely-praised book provides a framework for the many voices calling for the reaffirmation of democratic values, citizenship, and service in the public interest. 